\title{
Forest Activities for Developing Emotional Vocabulary and Lowering Cortisol Levels in Kindergarteners
}

\author{
Suk Young Yun*, Ga Ae Seol, Hyun Hee Jang, Mi Jin Kim, and Byung Jin Choi \\ Department of Horticulture, Daegu Catholic University, Gyeongsan 38430, Korea
}

\section{ABSTRACT}

The purpose of this study was to investigate the effects of forest activities on the cortisol concentrations in the body and emotional vocabulary of kindergarteners. The participants were 36 kindergarten children aged 4-5, 17 in the control group and 19 in the experimental group. Forest activities consisted of six steps according to the level of kindergarteners, and the program was carried out at G City Environment Training Institute. Before and after the experiment, the children's emotional vocabulary was self-reported and salivary cortisol was analyzed to evaluate changes in the body 's stress hormones. As a result, in the control group, positive words increased significantly from 0.14 to 1.53 ( $p=.003$ ), but the decrease in negative words was not significant ( $p=.059)$. In the experimental group, positive words increased significantly from 0.47 to 2.84 after forest activities $(p=.000)$. Negative words decreased significantly from 1.94 to 0.00 after forest activities $(p=.000)$. In the analysis of salivary cortisol, the change in salivary cortisol concentrations was not significant ( $p=.667)$ in the control group, merely decreasing from $0.179 \mu \mathrm{g} / \mathrm{dl}$ to $0.161 \mu \mathrm{g} / \mathrm{dl}$. However, the experimental group showed a significant decrease from $0.202 \mu \mathrm{g} / \mathrm{dl}$ to $0.161 \mu \mathrm{g} / \mathrm{dl}$ after forest activities $(p=.049)$. These results suggest that forest play activities may be helpful in encouraging young children's emotional development by increasing positive vocabulary and decreasing negative vocabulary and reducing stress in kindergarteners.

Keywords: negative vocabulary, positive vocabulary, saliva cortisol

\section{Introduction}

The increase in the income level, standards of living and parents' level of education, and the low birth rates lead to more and more attention in children's life and education. Too much expectations for and interest in children put them under a great deal of stress. Stress is caused by the pressure in daily life, and continuous pressure makes one suffer both mentally and physically (Jeong and Lee, 2009). Preschool children also tend to focus on intellectual development than play due to the trend of early education and are growing up into selfish, emotionally unstable and aggressive children that do not get along well with peers, having no chance to learn how to care for others (E.S. Kim, 2013).
The environment has also changed into a learning space that is inappropriate and dangerous for children to play due to industrialization, urbanization and concentration of population. Accordingly, children living in the city are deprived of any chance to explore the nature, spending more and more time indoors playing video or computer games in a dreary environment (Park and Huh, 2010).

Since the 2000s, there have been demands for nature-friendly educational programs to heal children's physical, emotional and social damages caused by the harmful consequences from modern civilization and industrialization. This increased the period of early childhood education in which nature-friendly or ecological education is provided using forests, vegetable gardens in parks, tidal flats and

This paper was funded by the research funds of Daegu Catholic University in 2018.

Received: May 8, 2019, Revised: May 31, 2019, Accepted: July 11, 2019

First author: Suk Young Yun, yune1004@cu.ac.kr, (D) https://orcid.org/0000-0002-5862-0021

*Corresponding author: Suk Young Yun, yune1004@cu.ac.kr, (10) https://orcid.org/0000-0002-5862-0021 
wetlands (Kwak et al., 2011). In addition, studies are also actively conducted on forest play of preschool children, proving that play activities in forest programs improved scientific inquiry skills and respect for life (Lee and Choi, 2015) and that forest play activities improved intimacy, sense of belonging, emotional awareness, mutual/public awareness and participation for preschool children aged 5 (Jang and Chung 2018). Forest play activities have positive effects on improving emotion regulation abilities and reducing problem behaviors for preschool children (S.H. Kim et al., 2015) and have positive effects on reducing daily stress of preschool children aged 4-5 (Lee, 2014). Moreover, there was a study determining preschool children's stress by examining the internalization and daily cortisol rhythm of children in institutional care and adopted children (Seol, 2012). There are also other studies physiologically determining preschool children's stress by examining the changes in cortisol concentration, such as analyzing the cortisol patterns according to childcare characteristics of preschool children in the low-income and middle class (Park et al., 2007) or conducting a correlation analysis on the cortisol level with stress of 2-year old children in the period of adaptation to a daycare center at the beginning of the semester (Park et al., 2012).

Meanwhile, language is an important means of communication and thinking process for human beings, and the most fundamental component of language is vocabulary. Emotion or emotional vocabulary is the most fundamental form of vocabulary in expressing emotions in words. It is discovered that preschool children who participated in an emotion vocabulary program with different situations showed an increase in emotional awareness and emotion regulation skills (Han and Park, 2016). Forest activities increased the number of expressive words, number of sentences and length of sentences, thereby improving preschool children's verbal expression skills (Lee, 2008). Literary activities in the forest are also proved to have effect on increasing verbal expression skills (Oh, 2010), and physical expression activities in association with forest experience have effect on improving preschool children's language skills (Cho, 2019).

Accordingly, this study investigates the effects of forest play activities on the changes in preschool children's emo- tional vocabulary by examining kindergarteners aged 4-5, examines salivary cortisol which is a stress hormone as a biochemical reaction of stress in the body and determines its effect on the changes in preschool children's emotional awareness and physiological change of stress.

\section{Research Methods}

\section{Subjects and research period}

This study is conducted on children aged 4-5 attending $\mathrm{L}$ and S Daycare Center located in the same administrative district of G city. Seventeen preschool children in L Daycare Center who agreed to collect salivary cortisol were assigned to the control group, and 19 preschool children in S Daycare Center who agreed to participate in forest play and collect salivary cortisol were assigned to the experimental group (forest play group). The forest play program was carried out and the salivary cortisol was collected in November 2018.

\section{Research tools}

\section{Forest play program}

The forest play program used in this study was Environment One, Two, Three (Ministry of Environment Certification No. 2014-119), an environment program for elementary school students carried out by the Environment Training Institute, which was reorganized and adjusted to meet the level of preschool children. This program consists of various activities such as pairing, throwing pine cones, making nests, climbing ropes blindfolded, making frames of natural objects, solving mazes in the forest, playing traditional games, observing nature with a loupe and picking cookies through the eyes of insects, most of which are focused on forest play for lower-grade elementary school students. This study formed the program in total 6 steps, reflecting the views of the kindergarten director, early childhood teachers and professional instructors of the Environment Training Institute and considering the level of preschool children and the one-hour time limit of the program. It was carried out while moving around in the forest at the Environment Training 
Institute. Step 1 was exciting preschool children's five senses by observing young leaves and barks in the forest, Step 2 was guessing and matching the animal sounds in the forest, Step 3 was observing aquatic ecology such as water hyacinth, lotus and frogs, and Step 4 was using a loupe to observe natural objects. Step 5 was dividing pieces of wood into different directions and readjusting them, and Step 6 was throwing pine cones into the target point. The time for each step was added or subtracted depending on the changes of the natural environment in November, and the total time spent for the program was one hour in the morning, considering the time to collect cortisol saliva and assess emotional vocabulary. The children from S Daycare Center, the forest play group, went to the Environment Training Institute to participate in the program, and professional instructors of the Environment Training Institute led the program. Safety education was provided for preschool children before they went into the forest for the program (Fig. 1).

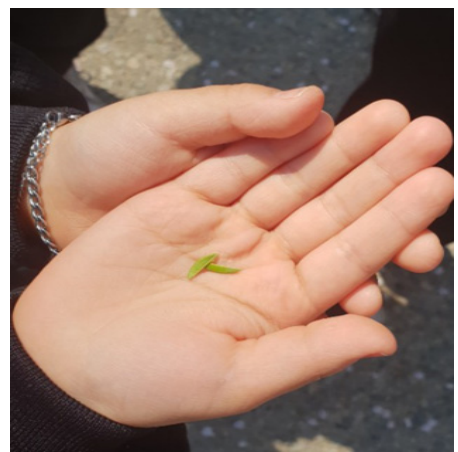

Step 1. Forest observation

(Observing young leaves or barks of the tree)

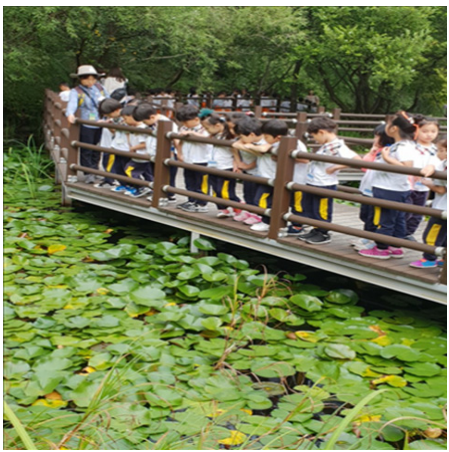

Step 3. Water ecology observation

(Observing Eichhornia crassipes, Nelumbo mucifera, frog, etc.)

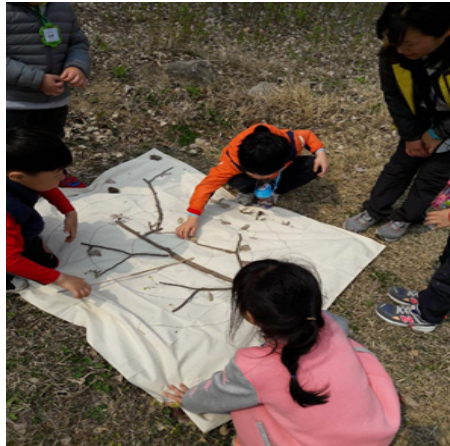

Step 5. Tree branches game (Arranging tree branches into different directions)

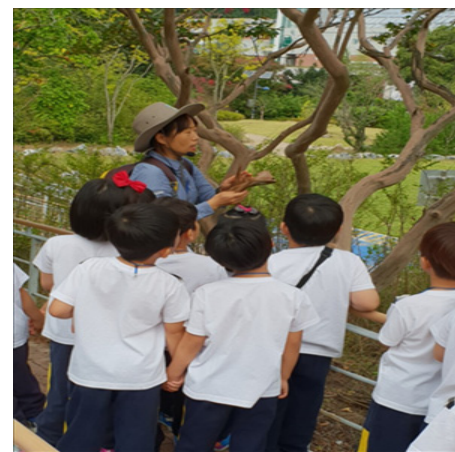

Step 2. Forest sounds

(Matching animal sounds in the woods)

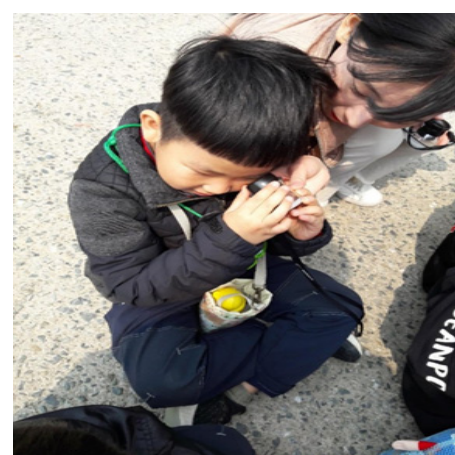

Step 4. Nature observation

(Observing natural objects using a loupe)

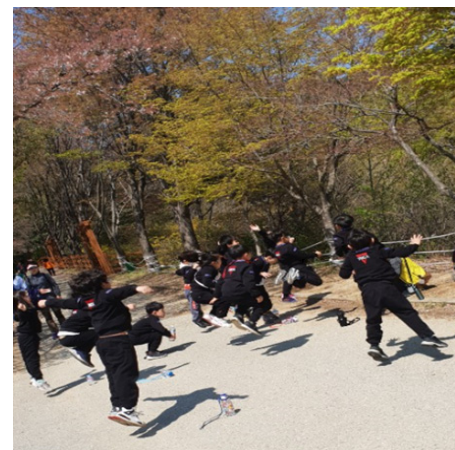

Step 6. Pine cone pitch

(Throwing pine cones to the target)

Fig. 1. Forest activities for kindergarteners. 


\section{Assessment tools}

(1) Assessment of emotional vocabulary

Emotional vocabulary is assessed using total 170 emotional words (49 positive words, 109 negative words, 13 neutral words) presented in the Korean language textbooks for learners studying Korean as a foreign language, modifying them to meet the level of preschool children (Park, 2013). This study first presented 170 emotional words that can be recognized by kindergarteners to kindergarten director and teachers and had them choose, extracting 77 words with high frequency of selection. These 77 words are then presented to 79 kindergarteners aged 4-5 and had them choose the ones they recognize. The assessment form was then made by extracting seven positive and seven negative words with high frequency of selection. The positive words were "love, interesting, confident, fun, thankful, good, exciting" and the negative words were "shabby, scary, bored, not fun, dull, upset, hate". The positive and negative words were randomly listed and arranged on the form. The assessment was made by having the subjects self-report their mood before and after the forest play activities, according to the statement "How do I feel right now? Circle (O) all of your feelings."

(2) Salivary cortisol analysis

Saliva collection for salivary cortisol analysis was done after submitting all the papers necessary such as request for protocol review, protocol, consent form and explanatory notes for subjects, and certificate on completion of bioethics training and then obtaining approval from the Institutional Review Board (CUIRB-2018-0045). Saliva collection for the salivary cortisol test was carried out at 11:30 a.m. before the program for both groups. After the program, saliva was collected from the control group after 1 hour of the regular curriculum at the daycare center, and from the forest play group after 1 hour of forest play. Saliva collection was done before filling out the assessment form so that stress increase from making the assessment does not affect the saliva sampling. The children were prohibited from eating any kind of food including chewing gum or candy starting from 1 hour before saliva collection. Saliva was collected using the Salivettes system presented in the methodology for saliva examination to measure salivary cortisol
(Choi et al., 2014). The swab from the Salivette ${ }^{\circledR}$ Cortisol (Art. No. 51, 1534, 500) by Sarstedt (Germany) was used for saliva examination according to the instructions provided by Sarstedt: The participant holds or chews the swab in the mouth for 60 seconds, then returns the swab into the tube, replacing the stopper to keep it closed. Then the tube refrigerated, after which it is sent to an analysis agency. The samples were sent within 24 hours of collection. The salivary cortisol analysis was requested to the specialized analysis team at Samkwang Medical Laboratories (www.smlab.co.kr).

\section{Data analysis}

Data collected was analyzed after statistical processing using IBM SPSS Statistics 19.0 Program. The homogeneity between the control group and experimental group before and after forest play was tested using the Mann-Whitney $\mathrm{U}$ test, and the changes in emotional vocabulary and cortisol concentration before and after forest play were determined by analyzing the mean difference using the Wilcoxon signed-rank test.

\section{Results and Discussion}

\section{Changes in emotional vocabulary}

\section{Test of homogeneity before the program}

Table 1 shows the result of conducting the Mann-Whitney $\mathrm{U}$ test to determine the homogeneity of emotional vocabulary between the control group and forest play group before the program. The mean of positive words was 0.41 for the control group and 0.47 for the forest play group, showing no significant difference $(p=.769)$. The mean of negative words was 1.47 for the control group and 1.94 for the forest play group, showing no significant difference $(p=.208)$. Therefore, the two groups are considered homogeneous, thereby proving effectiveness of changes in emotional vocabulary before and after forest play.

\section{Differences between groups after the program}

Table 2 shows the result of conducting the Mann-Whitney $\mathrm{U}$ test to determine the changes in emotional vocabulary 
of the control group and forest play group after the program. The mean of positive words was 1.53 for the control group and 2.84 for the forest play group, showing a significant difference $(p=.007)$. The mean of negative words was 1.18 for the control group and 0.00 for the forest play group, showing a significant difference $(p=.002)$. Therefore, this proves the effectiveness of changes in emotional vocabulary due to forest play activities.

\section{Changes in emotional vocabulary within the group}

Table 3 shows the result of investigating and analyzing emotional vocabulary before and after forest play. The control group participated in the regular curriculum indoors at the daycare center for 1 hour in the morning, and the mean of positive words increased significantly from 0.14 to 1.53 after the program $(p=.003)$. The group that partici- pated in 1 hour of forest play showed a greater increase and significance than the control group from 0.47 to 2.84 after forest play $(p=.000)$. There was an increase in the number of positive words, which was in line with the result of previous research proving that forest activities increased preschool children's language expression abilities by increasing the number of expressive words like adjectives, adverbs and determiners (Lee, 2008). The mean of negative words decreased from 1.47 to 1.18 in the control group but did not show significance $(p=.059)$, whereas the mean decreased significantly in the experimental group from 1.94 to 0.00 . The result had great significance because all 19 kindergarteners did not choose any negative words after forest play $(p=.000)$. This result is consistent with the research that preschool children who experienced forest play activities showed a more significant decrease in problem

Table 1. The pre-homogeneity test for emotional vocabulary in the control and experimental group

\begin{tabular}{cllcccc}
\hline \multicolumn{1}{c}{ Item } & \multicolumn{1}{c}{ Group } & $\mathrm{n}$ & $\mathrm{M}$ & $\mathrm{SD}$ & $\mathrm{z}$ & \multicolumn{2}{c}{$p$} \\
\hline Positive vocabulary & Control & 17 & 0.41 & 0.62 & -0.293 & $.769^{\mathrm{NS}}$ \\
& Experimental & 19 & 0.47 & 0.90 & & \\
\multirow{2}{*}{ Negative vocabulary } & Control & 17 & 1.47 & 1.23 & -1.258 & $.208^{\mathrm{NS}}$ \\
& Experimental & 19 & 1.94 & 1.18 & & \\
\hline
\end{tabular}

${ }^{\mathrm{NS}}$ Non-significant at $p<.05$ by Mann-Whitney U test.

Table 2. Differences in emotional vocabulary between groups after implementation of forest activities

\begin{tabular}{|c|c|c|c|c|c|c|}
\hline Item & Group & $\mathrm{n}$ & M & SD & $\mathrm{z}$ & $p$ \\
\hline \multirow[t]{2}{*}{ Positive vocabulary } & Control & 17 & 1.53 & 1.37 & -2.750 & $.007^{* *}$ \\
\hline & Experimental & 19 & 2.84 & 1.34 & & \\
\hline \multirow[t]{2}{*}{ Negative vocabulary } & Control & 17 & 1.18 & 1.13 & -3.827 & $.002^{* *}$ \\
\hline & Experimental & 19 & 0.00 & 0.00 & & \\
\hline
\end{tabular}

${ }^{* *} p<.01$ by Mann-Whitney U test.

Table 3. Comparison of pre- to post test changes in emotional vocabulary within the group

\begin{tabular}{|c|c|c|c|c|c|c|c|c|}
\hline \multirow{2}{*}{ Item } & \multirow{2}{*}{ Group } & \multirow{2}{*}{$\mathrm{n}$} & \multicolumn{2}{|c|}{ Pre test } & \multicolumn{2}{|c|}{ Post test } & \multirow{2}{*}{$\mathrm{z}$} & \multirow{2}{*}{$p$} \\
\hline & & & M & SD & M & SD & & \\
\hline \multirow[t]{2}{*}{ Positive vocabulary } & Control & 17 & 0.41 & 0.62 & 1.53 & 1.37 & -0.292 & $.003^{* *}$ \\
\hline & Experimental & 19 & 0.47 & 0.90 & 2.84 & 1.34 & -3.533 & $.000^{* * *}$ \\
\hline \multirow[t]{2}{*}{ Negative vocabulary } & Control & 17 & 1.47 & 1.23 & 1.18 & 1.13 & -1.890 & $.059^{\mathrm{NS}}$ \\
\hline & Experimental & 19 & 1.94 & 1.18 & 0.00 & 0.00 & -3.593 & $.000^{* * *}$ \\
\hline
\end{tabular}

${ }^{\text {NS }}$ Non-significant, ${ }^{* *} p<.01,{ }^{* * *} p<.001$ by Wilcoxon signed-rank test. 
behavior than those who did not (S.H. Kim et al., 2015), that horticultural activities in the classroom reduced elementary school students' negativity, excitement, violence, and verbal or indirect aggression (Jeong and Lee, 2009), and that forest experience reduced children's rage and aggression (I.J. Kim, 2013), thereby proving that forest play is effective in reducing negative words of preschool children.

Table 4 shows the result of examining changes in positive and negative vocabulary after forest play activities by word. The control group chose positive words seven times before the regular curriculum in the morning and 26 times after, whereas the experimental group chose positive words nine times before forest play and 54 times after. In the control group, there was a high frequency of fun (28.57\%) and good (28.57\%) among positive words before the program, and good (30.77\%) and interesting (30.77\%) after the program. In the experimental group, there was a high frequency of good $(33.33 \%)$ and fun $(22.22 \%)$ before forest play, and exciting (25.07\%), good (27.07\%), fun $(20.37 \%)$, and interesting (20.37\%) after forest play, expressing more diverse words. This result is consistent with the research finding that literary activities in a forest kindergarten increased preschool children's number of ex- pressive words and sentences, thereby improving overall language expression abilities (Oh, 2010). The control group chose negative words 25 times before the class and 20 times after, whereas the experimental group chose negative words 37 times before forest play and 0 times after, proving that forest play is effective in reducing negative words. More specifically, in the control group, there was a high frequency of not fun (36.00\%), bored $(28.00 \%)$, and dull $(20.00 \%)$ among negative words before the program, and bored $(40.00 \%)$, not fun $(30.00 \%)$, and dull $(20.00 \%)$ after the program. In the experimental group, there was a high frequency of bored (29.73\%), not fun (29.73\%), and dull $(21.62 \%)$ before forest play, but there was no negative word after forest play. No preschool children in both groups chose the words shabby and hate regardless of forest play.

\section{Changes in salivary cortisol concentrations}

\section{Test of homogeneity before the program}

As a result of conducting the Mann-Whitney $U$ test to determine the homogeneity of salivary cortisol between the control group and forest play group, the mean of the control group was $0.179 \mu \mathrm{g} / \mathrm{dl}$ and the mean of the forest play

Table 4. Frequency changes in emotional vocabulary from pre- to post test in the control and experimental group

\begin{tabular}{|c|c|c|c|c|c|c|c|c|c|}
\hline \multirow{2}{*}{\multicolumn{2}{|c|}{ Item }} & \multicolumn{4}{|c|}{ Control } & \multicolumn{4}{|c|}{ Experimental } \\
\hline & & \multicolumn{2}{|c|}{ Pre test $(\%)$} & \multicolumn{2}{|c|}{ Post test (\%) } & \multicolumn{2}{|c|}{ Pre test $(\%)$} & \multicolumn{2}{|c|}{ Post test (\%) } \\
\hline \multirow{8}{*}{$\begin{array}{c}\text { Positive } \\
\text { vocabulary }\end{array}$} & Love & 1 & (14.29) & 1 & $(3.85)$ & 0 & $(0.00)$ & 2 & $(3.70)$ \\
\hline & Thank you & 1 & (14.29) & 0 & $(0.00)$ & 1 & (11.11) & 4 & (7.41) \\
\hline & Be confident & 0 & $(0.00)$ & 0 & $(0.00)$ & 1 & (11.11) & 0 & $(0.00)$ \\
\hline & Exciting & 0 & $(0.00)$ & 5 & (19.23) & 1 & (11.11) & 13 & (24.07) \\
\hline & Fun & 2 & $(28.57)$ & 4 & (15.38) & 2 & $(22.22)$ & 11 & (20.37) \\
\hline & Good & 2 & $(28.57)$ & 8 & (30.77) & 3 & (33.33) & 13 & (24.07) \\
\hline & Interesting & 1 & (14.29) & 8 & (30.77) & 1 & (11.11) & 11 & (20.37) \\
\hline & Total & 7 & $(100)$ & 26 & $(100)$ & 9 & $(100)$ & 54 & $(100)$ \\
\hline \multirow{8}{*}{$\begin{array}{c}\text { Negative } \\
\text { vocabulary }\end{array}$} & Shabby & 0 & $(0.00)$ & 0 & $(0.00)$ & 0 & $(0.00)$ & 0 & $(0.00)$ \\
\hline & Dull & 5 & (20.00) & 4 & $(20.00)$ & 8 & (21.62) & 0 & $(0.00)$ \\
\hline & Bored & 7 & $(28.00)$ & 8 & $(40.00)$ & 11 & (29.73) & 0 & $(0.00)$ \\
\hline & Scary & 1 & $(4.00)$ & 1 & $(5.00)$ & 5 & (13.51) & 0 & $(0.00)$ \\
\hline & Hate & 0 & $(0.00)$ & 0 & $(0.00)$ & 0 & $(0.00)$ & 0 & $(0.00)$ \\
\hline & Not funny & 9 & $(36.00)$ & 6 & $(30.00)$ & 11 & (29.73) & 0 & $(0.00)$ \\
\hline & Upset & 3 & $(12.00)$ & 1 & $(5.00)$ & 2 & $(5.41)$ & 0 & $(0.00)$ \\
\hline & Total & 25 & $(100)$ & 20 & (100) & 37 & (100) & 0 & (100) \\
\hline
\end{tabular}


group was $0.202 \mu \mathrm{g} / \mathrm{dl}$, thereby showing no significant difference $(p=.073)$. Therefore, the two groups are considered homeogenous, thereby proving effectiveness of changes in salivary cortisol before and after forest play (Table 5).

\section{Difference between groups after the program}

Table 6 shows the result of conducting the Mann-Whitney $\mathrm{U}$ test to determine the changes in salivary cortisol of the control group and forest play group after the program. The mean was $0.161 \mu \mathrm{g} / \mathrm{dl}$ for the control group and 0.161 $\mu \mathrm{g} / \mathrm{dl}$ for the forest play group, showing no significant difference $(p=.007)$. The salivary cortisol level of the forest play group decreased slightly more than before, but there was no significant difference compared to the control group.

\section{Changes in salivary cortisol concentrations}

As a result of examining salivary cortisol concentrations to determine the effects of forest play on reduction of preschool children's stress, the control group did not show a significant change in salivary cortisol concentrations from $0.179 \mu \mathrm{g} / \mathrm{dl}$ to $0.161 \mu \mathrm{g} / \mathrm{dl}$ after 1 hour of regular curriculum $(p=.667)$. However, the experimental group showed a sig- nificant decrease from $0.202 \mu \mathrm{g} / \mathrm{dl}$ to $0.161 \mu \mathrm{g} / \mathrm{dl}$ after forest play ( $p=.049$; Table 7). This result is consistent with the study proving that phytoncide therapy from walking in the forest lowered male adults' cortisol concentrations (Lee and Lee, 2012). It was also in line with the study that carried out overnight forest activities for mentally vulnerable children from low-income families, examined cortisol concentration, self-esteem and attitude toward the forest and discovered that forest activities lowered cortisol concentrations and anxiety while improving self-esteem and attitude toward the forest (S.A. Kim et al., 2015), physiologically proving that forest play was effective in reducing preschool children's stress.

Overall, kindergarteners aged 4-5 showed an increase in positive words and decrease in negative words after forest play activities, as well as reduction of salivary cortisol, which is a stress hormone. This is consistent with the result that preschool children aged 5 that participated in art integration activities in a nature-friendly method at a kindergarten forest playground showed reduction of stress in criticism and aggression (Kim and Kim, 2015). This implies that forest play activities comprised of various play activ-

Table 5. The pre-homogeneity test for saliva cortisol in the control and experimental group

\begin{tabular}{ccccccc}
\hline Item & Group & $\mathrm{n}$ & $\mathrm{M}$ & $\mathrm{SD}$ & $\mathrm{z}$ & $p$ \\
\hline Cortisol $(\mu \mathrm{g} / \mathrm{dl})$ & Control & 17 & 0.179 & 0.139 & \multirow{2}{*}{1.793} & $.073^{\mathrm{NS}}$ \\
& Experimental & 19 & 0.202 & 0.107 & & \\
\hline
\end{tabular}

${ }^{\mathrm{NS}}$ Non-significant at $p<.05$ by Mann-Whitney U test.

Table 6. Differences in cortisol levels between groups after implementation of forest activities

\begin{tabular}{ccccccc}
\hline Item & Group & $\mathrm{n}$ & $\mathrm{M}$ & $\mathrm{SD}$ & $\mathrm{z}$ & $p$ \\
\hline Cortisol $(\mu \mathrm{g} / \mathrm{dl})$ & Control & 17 & 0.161 & 0.087 & \multirow{2}{*}{0.334} & $.754^{\mathrm{NS}}$ \\
& Experimental & 19 & 0.161 & 0.041 & & \\
\hline
\end{tabular}

${ }^{\mathrm{NS}}$ Non-significant at $p<.05$ by Mann-Whitney U test.

Table 7. Comparison of pre- to post test changes in cortisol levels within the group

\begin{tabular}{|c|c|c|c|c|c|c|c|c|}
\hline \multirow{2}{*}{ Item } & \multirow{2}{*}{ Group } & \multirow{2}{*}{$\mathrm{n}$} & \multicolumn{2}{|c|}{ Pre test } & \multicolumn{2}{|c|}{ Post test } & \multirow{2}{*}{$\mathrm{z}$} & \multirow{2}{*}{$p$} \\
\hline & & & M & SD & $\mathrm{M}$ & SD & & \\
\hline \multirow[t]{2}{*}{ Cortisol ( $\mu \mathrm{g} / \mathrm{dl})$} & Control & 17 & 0.179 & 0.139 & 0.161 & 0.087 & -0.416 & $.677^{\mathrm{NS}}$ \\
\hline & Experimental & 19 & 0.202 & 0.107 & 0.161 & 0.041 & -1.971 & $.049^{*}$ \\
\hline
\end{tabular}

${ }^{\mathrm{NS}}$ Non-significant, ${ }^{*} p<.05$ by Wilcoxon signed-rank test. 
ities with nature observation and natural objects help relieve tension and reduce stress by feeling a sense of freedom and making direct contact with nature rather than being in a competition, thereby reducing negative words and salivary cortisol concentrations. Education in the forest on preschool children aged 4-5 had a positive effect on prosocial skills of preschool children, especially those who participated in education 5 days a week compared to those who participated twice a week (Kim, 2013). This indicates that, by developing various forest play programs and constantly carrying out forest play activities, it will be possible to increase positive words and decrease negative words of kindergarteners, while also having a positive effect on reducing stress, thereby helping them secure emotional stability.

\section{Conclusion}

This study was conducted to determine the effects of forest play activities on emotional vocabulary and physiological change in stress of kindergarteners. Positive words of the control group increased significantly from 0.14 to 1.53 after 1 hour of regular curriculum $(p=.003)$, but there was no significance in the decrease of negative words $(p=.059)$. However, for the experimental group, positive words increased from 0.47 to 2.84 after forest play $(p=.000)$, and negative words decreased significantly from 1.94 to 0.00 as well $(p=.000)$. Furthermore, as a result of analyzing salivary cortisol to determine the physiological change in stress, the control group did not show a significant change in salivary cortisol concentrations from 0.179 to $0.161 \mu$ $\mathrm{g} / \mathrm{dl}$ after 1 hour of regular curriculum $(p=.667)$, but the experimental group showed a significant decrease from 0.202 to $0.161 \mu \mathrm{g} / \mathrm{dl}$ after forest play $(p=.049)$. The results showed that forest play activities increased positive words and decreased negative words as well as salivary cortisol concentrations of preschool children, thereby improving their vocabulary and reducing stress. There must be more opportunities for preschool children to participate in regular forest play activities so that they can enjoy a healthier life.

\section{References}

Cho, Y.J. 2019. The effects of physical expression activities linked to forest activities on young children's language ability, motor proficiency ability, and sense of self-esteem. Early Child. Educ. Res. Rev. 23(1):285-309. https://doi.org/10.32349/ECERR.2019.2.23.1.285

Choi, S.H., I.S. Lee, I.J. Song, O.J. Kwon, K.E. Park, H.J. Hong, K.K. Sung, and S.K. Lee. 2014. Method of saliva collection for salivary cortisol measurement. Korean J. Orient. Physiol. Pathol. 28(2):223-224.

Han, J.H. and C.O. Park. 2016. The effect of emotional vocabulary expression program for young children according to situations on emotional recognition ability and emotion regulation ability. Early Child. Educ. Res. Rev. 20(5):447-466.

Jang, J.Y. and K.S. Chung. 2018. A study on the effectiveness of play activities in forest to improve children's community spirit. J. Korea Open Assoc. Early Child. Educ. 23(5):269-292. https://doi.org/10.20437/KOAECE23-5-12

Jeong, Y.O. and J.H. Lee. 2009. The influence of in-classroom horticultural activities on the reduction of elementary school students' aggression and stress. J. Korean Pract. Arts Educ. 22(4):151-172.

Kim, E.S. 2013. Impact of play in forest on children's pro-social ability. J. Korea Open Assoc. Early Child. Educ. 18(4):205-229.

Kim, I.J. 2013. The influence of a forest experience program on elementary student's anger and aggression from low income families. Master's thesis, Chungbuk National University, Cheongju, Korea.

Kim. S.A., D.W. Joung, D.G. Yeom, G.W. Kim, and B.J. Park. 2015. The effects of forest activities on attitudes toward forest, stress, self-esteem and mental health of children in community child centers. J. Korean Inst. For. Recreat. 19(3):51-58.

Kim, S.H., H.J. Park, and S.Y. Kim. 2015. The effects of forest play activity on young children's emotional regulation ability and problem behavior. Korea $\mathrm{J}$. Child Care Educ. 90:1-21.

Kim, S.H. and H.S. Kim. 2015. The effects of the na- 
ture-friendly integrated art activity on children's daily stress and social and development. J. Korean Counc. Child. Rights 19(4):611-637.

Kwak, N.U., D. Kim, and E.J. Lim. 2011. A study based participant observation about educational activity of integrated forest kindergarten. J. Korea Elementary Educ. 22(3):153-173.

Lee, B.K. and H.H. Lee. 2012. A study on the effects of human physiology after forest phytoncide therapy. J. Naturopathy 1(1):14-20.

Lee, B.N. and M.S. Choi. 2015. The effects of play activities through a forest experience on young children's scientific inquiry ability and life respect attitude. J. Parent Educ. 7(1):53-66.

Lee, I.S. 2008. An influence of forest experience activity on child's language expression and nature-friendly attitude. Master's thesis, Sungshin Women's University, Seoul, Korea.

Lee, I.W. 2014. The effects of forest experience activities upon young children's daily stress reduction. J. Korea Open Assoc. Early Child. Educ. 19(6):83-103.

Oh, S.Y. 2010. Impact of literary activities in the forest on the verbal expressiveness of preschoolers: The case of a forest kindergarten attached to University of Incheon. Master's thesis, Incheon National University, Incheon, Korea.

Park, K.J., J.Y. Choi, Y.H. Kim, and J.H. Kim. 2007. Children's cortisol patterning at childcare centers. Korean J. Child Stud. 28(6):201-215.

Park, S.H. 2013. Study for emotional vocabulary on korean language textbook. Master's thesis, Soongsil University, Seoul, Korea.

Park, S.H. and M.R. Huh. 2010. Effect of a horticultural program on the preschool children's emotional intelligence and daily stress. Korean J. Hortic. Sci. Technol. 28(1):144-149.

Park, S.K., M.R. Chung, and J.Y. Kwon. 2012. The cortisol pattern of two year old toddlers during the adaptation period to a new class at childcare centers. J. Korea Open Assoc. Early Child. Educ. 17(4):485-501.

Seol. K.O. 2012. The diurnal cortisol regulation rhythm and internalizing problems of children in institutional care and adopted children in Korea. Korean J. Dev. Psychol. 25(3):73-87. 